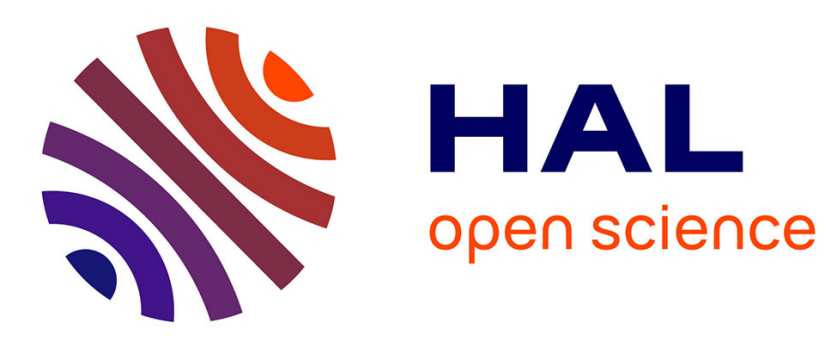

\title{
The role of mineral metabolism and inflammation on dialysis vascular access failure
}

\author{
Marion Morena, Jean-Yves Bosc, Isabelle Jaussent, Anne-Marie Dupuy, \\ Nathalie Terrier, Hélène Leray-Moragues, Jean-Louis Flavier, François \\ Maurice, Cécile Delcourt, Jean-Paul Cristol, et al.
}

\section{To cite this version:}

Marion Morena, Jean-Yves Bosc, Isabelle Jaussent, Anne-Marie Dupuy, Nathalie Terrier, et al.. The role of mineral metabolism and inflammation on dialysis vascular access failure. J Vasc Access, 2006, 7 (2), pp.77-82. inserm-00077642

\section{HAL Id: inserm-00077642 https://www.hal.inserm.fr/inserm-00077642}

Submitted on 28 Oct 2008

HAL is a multi-disciplinary open access archive for the deposit and dissemination of scientific research documents, whether they are published or not. The documents may come from teaching and research institutions in France or abroad, or from public or private research centers.
L'archive ouverte pluridisciplinaire HAL, est destinée au dépôt et à la diffusion de documents scientifiques de niveau recherche, publiés ou non, émanant des établissements d'enseignement et de recherche français ou étrangers, des laboratoires publics ou privés. 
THE ROLE OF MINERAL METABOLISM AND INFLAMMATION ON DIALYSIS VASCULAR ACCESS FAILURE

Running head: Mineral metabolism and failure of internal vascular access.

M Morena ${ }^{\mathrm{a}, \mathrm{b}}, \mathrm{JY}$ Bosc $^{\mathrm{c}}$, I Jaussent ${ }^{\mathrm{d}}$, AM Dupuy ${ }^{\mathrm{a}}, \mathrm{N}$ Terrier ${ }^{\mathrm{a}}, \mathrm{H}$ Leray-Moragues ${ }^{\mathrm{e}}$, JL Flavier ${ }^{\mathrm{c}}, \mathrm{F}$

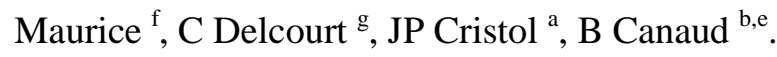

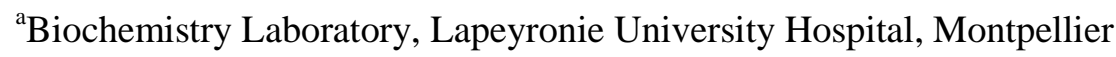

${ }^{\mathrm{b}}$ Renal Research and Training Institute, Montpellier

${ }^{\mathrm{c}}$ AIDER, Montpellier

${ }^{\mathrm{d}}$ French National Institute of Health and Medical Research, Inserm E 0361, Montpellier

${ }^{\mathrm{e}}$ Department of Nephrology, Lapeyronie University Hospital, Montpellier

${ }^{\mathrm{f}}$ Centre Hemodialyse Languedoc Méditerranée, Montpellier

${ }^{\mathrm{g}}$ French National Institute of Health and Medical Research, Inserm U593, Bordeaux

\section{Address correspondence to:}

Prof. Bernard CANAUD

Nephrology Department, Lapeyronie University Hospital

191, Avenue du Doyen Gaston Giraud

34295 Montpellier cedex 5, France

e-mail: b-canaud@chu-montpellier.fr

Phone: $33467338495 \quad$ Facsimile: 33467603783 


\section{AbSTRACT}

Thrombosis of arteriovenous fistula (AVF) is the leading cause of vascular access (VA) loss usually due to silent stenosis. Therefore, assessment of relevant risk factors of VA monitoring may provide insight into potential therapeutic targets for stenosis and thrombosis. The aim of this study was to evaluate the influence of cardiovascular risk factors (including inflammation and mineral metabolism dysfunctions) on the failure of internal AVF in HD patients.

128 HD patients with internal AVF were included in the study and followed up for two years. At baseline, VA morphology and function were followed by Doppler ultrasonography and serum albumin, prealbumine, C-reactive protein, orosomucoid, calcium, phosphorus, parathyroid hormone, bone-type alkaline phosphatase, osteoprotegerin and receptor activator of nuclear factor $\kappa \square \mathrm{B}$ ligand were measured.

At baseline, 50 stenoses were detected but none of them required any intervention. Age and biological parameters did not significantly differ between patients with or without VA stenosis. Over the two year- follow-up, VA thrombosis occurred in 19 patients. Preexisting stenosis of VA was present in 9/19 patients (47.3\% of cases) (chi-square=3.708, $\mathrm{p}=0.0538$ ). Despite the low rate of events, phosphorus [1.75(0.95-2.77) vs $1.42(0.47-3.22) \mathrm{mmol} / \mathrm{L}, \mathrm{p}=0.0416]$, CalciumxPhosphorus product [4.00(2.00-5.90) vs 3.40(1.10-6.80) $\left.\mathrm{mmol}^{2} / \mathrm{L}^{2}, \mathrm{p}=0.0676\right]$ and parathyroid hormone [165.00(1.00944.00) vs 79.50(1.00-846.60) $\mathrm{ng} / \mathrm{L}, \mathrm{p}=0.0814)$ levels were higher in the 19 thrombotic patients whereas all other biological parameters did not significantly differ.

These results, which confirm that VA thrombosis occurs more frequently upon preexisting stenosis, also demonstrate that mineral metabolism disorders, compared to inflammation, may contribute to VA dysfunction leading to thrombosis.

Key words: hemodialysis, vascular access, stenosis, thrombosis, mineral metabolism, cardiovascular risk. 


\section{INTRODUCTION}

Vascular access dysfunction is one major cause of morbidity in the hemodialysis (HD) population being responsible for approximatively $20 \%$ to $24 \%$ of all hospitalizations in the end stage renal disease population $(1,2)$. Thrombosis is the leading cause of arteriovenous fistula loss occurring in about $80 \%$ on a silent stenosis (3). Surgical technique of implantation, nurse handling and clinical practice are known to affect survival rate of arteriovenous fistula (4).

Despite the clinical relevance of this problem, it is frustrating to see the poor effectiveness of preventive treatment and/or preemptive corrective intervention on thrombosis rate. Therefore, assessment of relevant risk factors for internal arteriovenous fistula by vascular access monitoring may provide insight into potential therapeutic and earlier treatment for venous stenosis and thrombosis.

Stenotic lesions of internalized arteriovenous fistula vascular access exhibit neointimal hyperplasia in the venous outflow system (5) consisting of vascular smooth muscle cell proliferation, endothelial cell activation, extracellular matrix accumulation and angiogenesis (5-8), similarly to HD-induced arteriopathy $(9,10)$. Thus, one can speculate that in addition to local flow disturbances, stenotic lesions of internalized arteriovenous fistula vascular access may share same pathogenic mechanisms as those resulting in HD-induced accelerated atherosclerosis. Systemic factors linked to end stage renal failure or HD process such as inflammation (11), dyslipidemia $(9,12)$, oxidative stress or hyperparathyroidism have all been implicated. In particular, disturbances of calcium and phosphorus metabolism may play an important role in facilitating uremic vascular disease and calcifications . Vascular wall thickening in renal failure seems to be modified at least in part by the hyperparathyroidism of these patients (13). In experimental studies, a direct effect of high phosphorus diet in arterial wall thickening was also reported (14). Furthermore, increased calcification of coronary atherosclerotic plaques and of the media of the aorta and some peripheral arteries has been largely documented in this population.

Thus, the aim of the present study was to evaluate the interest of vascular access monitoring by Doppler ultrasonography and to analyze the role of systemic cardiovascular risk factors including 
inflammation and especially mineral metabolism indexes on the failure rate of internalized arteriovenous fistula vascular access in a cohort of HD patients over a two year-follow up period.

\section{METHODS}

\section{Study design and Patients}

The influence of inflammation and hyperparathyroidism on the occurrence of vascular access failure was evaluated in a cohort study of 128 chronic HD patients with internal accesses (either native (114 patients) or polytetrafluoroethylene (PTFE) graft (14 patients) arteriovenous fistulas) and treated

in three dialysis centers from the Montpellier area (the Lapeyronie University Hospital, the AIDER and the CHLM centers, Montpellier, France). The study started after all patients gave informed consent.

All patients were on HD since more than 12 months. 24 patients were diabetics. The median age of patients was 67.5 y.o. (22.3-86.6 y.o)

Vascular access patency was monitored by Doppler ultrasonography (Sonosite C180+, Sonosite Inc., Bothell, WA, USA) at baseline.

\section{Laboratory measurements}

At the beginning of the observation period, blood samples were collected, centrifuged and stored at $-80^{\circ} \mathrm{C}$ for biological analyses.

Albumin, prealbumin, high sensitive C-reactive protein (CRP) and orosomucoid were quantified by immunoturbidimetric method (Olympus apparatus, Rungis, France). Calcium (Ca) and phosphorus $\left(\mathrm{PO}_{4}\right)$ were assessed by colorimetric method (Olympus apparatus, Rungis, France). Parathyroid hormone $(\mathrm{PTH})$ was measured by immunoradiometric assay. Osteoprotegerin (OPG) and receptor activator of nuclear factor $\kappa \mathrm{B}$ ligand (RANKL) were determined by enzyme linked immunosorbent assay (ELISA) (Biovendor Laboratory Medicine, Brno, Czech Republic and Quidel Corporation respectively). Bone-type Alkaline Phosphatase (b-ALP) was measured by immunochemiluminescence technique (Access Beckman Coulter, Villepinte, France). 


\section{Statistical analysis}

Continuous variables were indicated as median $[\min -\max ]$ because all variables were not normally distributed.

The comparisons between patients with or without failure of vascular access were performed using Chi-square or Fisher Tests for qualitative variables and Mann-Whitney test for quantitative variables.

Significance level was set at $\mathrm{p}<0.05$.

\section{RESULTS}

\section{Patency of internal arteriovenous fistula vascular access at baseline}

From the 128 Doppler ultrasonographies (mean blood flow access Qa $=863.8(260-2000) \mathrm{mL} / \mathrm{min}$ ), 50 stenoses were detected, 16 being present on the proximal segment vein, 2 on the anastomosis and 32 on the distal segment vein (see Table 1) but none of them did require any intervention.

Interestingly, none of the systemic parameters including inflammatory and mineral metabolism markers were significantly associated to stenosis (data not shown). In addition, gender, age, diabetes, smoking habit, hematocrit, time spent in HD and dialysis efficiency (Kt/V) also did not significantly differ between patients with or without vascular access stenosis (data not shown).

\section{$\underline{\text { 2. Stenosis dramatically impaired vascular access after two years }}$}

After a two year- follow up period, failure of vascular access was registered in 19 of 128 patients. Among these 19 patients, 9 were previously presenting stenotic lesions at baseline corresponding to a $47.3 \%$ thrombosis occurring upon preexisting stenosis. Interestingly, all of the preexisting stenoses were detected on the distal segment vein (chi-square $=3.708, \mathrm{p}=0.0538)$.

\section{Influence of cardiovascular risk factors on vascular access failure}

As shown in Table 2, gender, age, diabetes, smoking habit, hematocrit, time spent in HD and reduced dialysis efficiency $(\mathrm{Kt} / \mathrm{V})$ were not significantly associated to vascular access failure. 
By contrast, high $\mathrm{PO}_{4}$ level was associated with a poor functional vascular access as demonstrated by significantly higher levels in patients with failure versus patients without failure of vascular access $\left[\mathrm{PO}_{4}\left[1.75(0.95-2.77)\right.\right.$ vs $1.42(0.47-3.22) \mathrm{mmol} / \mathrm{L}, \mathrm{p}=0.0416$ see Table 3]. Moreover, $\mathrm{CaxPO}_{4}$ product and PTH levels tended to be increased in patients with failure versus patients without failure of vascular access although this did not reach statistical significance $\left[\mathrm{CaxPO}_{4}\right.$ product $[4.00(2.00-$ 5.90) vs $\left.3.40(1.10-6.80) \mathrm{mmol}^{2} / \mathrm{L}^{2}, \mathrm{p}=0.0676\right]$ and PTH $[165.00(1.00-944.00)$ vs 79.50 (1.00-846.60) $\mathrm{ng} / \mathrm{L}, \mathrm{p}=0.0814]$ see Table 3]. Otherwise, all other biological parameters including inflammatory markers did not significantly differ in the 19 patients presenting failure of vascular access compared to patients with functional access (see Table 4).

\section{DISCUSSION}

Hemodialysis vascular access dysfunction is the single most important cause of morbidity in the HD population. It has been estimated that vascular access dysfunction was responsible for approximately $20 \%$ to $24 \%$ of all hospitalizations in the end stage disease population at a cost of $\$ 1$ billion per annum $(1,2)$. Therefore, determination of relevant risk factors for vascular access failure may provide new insight into vascular access monitoring. In our study, we investigated the role of vascular access stenosis and systemic vascular risk factors (inflammation and especially mineral metabolism indexes) as indicators of vascular access failure in a cohort of $128 \mathrm{HD}$ patients.

We confirmed that near of $50 \%$ of vascular access failure occurred upon preexisting stenosis after a two year- period of follow up. In contrast, we reported that parameters of mineral metabolism only, including phosphate, $\mathrm{Ca} \mathrm{X} \mathrm{PO}_{4}$ product and $\mathrm{PTH}$, did influence the failure of vascular access after two years whereas inflammatory markers did not change between the two populations of patients.

This study confirms that regular vascular access monitoring by ultrasonography provides a sensitive tool to detect asymptomatic venous stenosis and to anticipate thrombosis. Ultrasound, a noninvasive mean of detecting access dysfunctions, is sensitive in detection of vascular access stenosis by giving both morphologic characteristics and blood flow consequences. Ultrasound is also useful in the evaluation of other anatomical fistula abnormalities, such as pseudoaneurysm, steal syndrome, or 
infected thrombosis $(15,16)$. As a part of quality insurance, the regular monitoring and imaging of vascular access is required to improve access survival and outcomes (17). Curiously, reduced access flow was not predictive of thrombosis events. In only 3/9 stenoses that led to occlusion (33.3\%), Qa was below $400 \mathrm{~mL} / \mathrm{min}$. This result suggests that reduced access blood flow is not always associated with stenosis or predictive of thrombosis. Such findings are in agreement with recent data of Ram et al. who reported a randomized controlled trial showing that blood flow surveillance of PTFE graft (Qa) and stenosis detection did not improve graft survival (18). Interestingly, all stenoses detected in our study and leading to occlusion were located distally on the vein and not proximally or close to arteriovenous anastomosis as it is usually reported (4). Interestingly, some authors have suggested that distal stenotic lesions may be attributable to calcium overload especially in diabetic and in long term treated HD patients (P. Bourquelot, unpublished data). Focusing on this aspect, as well as the fact that calcium phosphate deposits into stenotic lesions, as observed by Olsson et al. (19), we can assume that vascular calcifications may strongly participate to the patency rate of vascular access (20) all the more because arteriovenous fistula is now well recognized as a model of atherogenesis (as reported by Zou et al. in mouse (21)). Therefore, we further explored the role of calcifying factors involved in the atherosclerotic plaque process (especially mineral metabolism indexes and inflammation) on the failure of vascular access.

The relationship between secondary hyperparathyroidism of HD patients and accelerated atherogenesis, has been suggested by several authors based mainly on clinical observations (13). Vascular wall thickening in renal failure seems to be affected by parathyroid hormone (PTH) level (13). A direct effect of high phosphorus diet in arterial wall thickening was also reported (14). Our study shows that high concentrations in calcium and phosphate may play a role in vascular access failure. These data are in agreement with the results of Grandaliano et al. (22) who identified significant differences in phosphorus, $\mathrm{CaXPO}_{4}$ product and $\mathrm{PTH}$ concentrations between HD patients with or without failure of vascular access. Since it has been recently suggested that vascular calcification, a major prognosis factor in HD patients (23), was an active phenomenon secondary to vascular smooth muscle cell transdifferentiation in osteoblasts, we then decided to explore the regulatory factors of such differentiation, the OPG/RANKL system. Indeed, OPG and RANKL have 
emerged as a key agonist/antagonist cytokine system that regulates important aspects of osteoclast/ osteoblast formation $(24,25)$. RANKL increases the pool of active osteoclasts by activating its specific receptor RANK located on osteoclastic cells, thus increasing bone resorption, whereas OPG, which neutralizes RANKL, has opposite effects. RANKL and OPG are produced by bone marrow derived stromal cells and osteoblasts and are regulated by various calcitropic cytokines, hormones, and drugs. Interestingly, it has been shown in general populations that increased levels of OPG was associated with an increased rate of cardiovascular mortality due to vascular calcifications (26). Regarding the influence of these bone markers on vascular access failure, no association between calcification related- proteins, OPG or RANKL, and thrombosis of vascular access was identified in our study.

Finally, we explored the role of inflammatory markers on vascular access failure. Indeed, chronic micro-inflammation, as testimony by elevated CRP, is a common feature of HD patients predicting progression of coronary atherosclerosis $(27,28)$. In this context, it has been shown that inflammation conspires with malnutrition and atherogenesis leading to the MIA (malnutrition, inflammation, and atherosclerosis) syndrome (29). This association was premise to our hypothesis. Therefore it was expected that CRP and nutritional markers (albumin and prealbumin) would strongly influence failure, at least stenosis, of internalized vascular access. Results of our study are not substantiating this hypothesis, since neither CRP nor orosomucoid, another inflammatory marker, were associated with access failure. To our knowledge, it is the first time that the role of micro-inflammation such as CRP on incidence of native fistula thrombosis was explored, except a report of an association between high plasma fibrinogen and vascular access failure (30). Malnutrition markers did not influence the prognosis of internalized vascular access as well: no association was observed between failure of access and serum albumin or prealbumin levels.

In conclusion, these results confirm the fact that failure of internalized vascular access occurs usually after preexisting stenosis. Disorders of calcium and phosphate metabolism may actively contribute to vascular access dysfunction whereas inflammation is not associated. Further studies are needed to understand mechanisms by which calcium and phosphate metabolism disorders impaired vascular access survival. 


\section{REFERENCES}

1. Feldman HI, Kobrin S, Wasserstein A. Hemodialysis vascular access morbidity. J Am Soc Nephrol 1996; 7:523-535

2. Rayner HC, Pisoni RL, Bommer $J$, et al. Mortality and hospitalization in haemodialysis patients in five European countries: results from the Dialysis Outcomes and Practice Patterns Study (DOPPS). Nephrol Dial Transplant 2004; 19:108-120

3. Sukhatme VP. Vascular access stenosis: prospects for prevention and therapy. Kidney Int 1996; 49:1161-1174

4. Mickley V. Stenosis and thrombosis in haemodialysis fistulae and grafts: the surgeon's point of view. Nephrol Dial Transplant 2004; 19:309-311

5. Beathard GA. The treatment of vascular access graft dysfunction: a nephrologist's view and experience. Adv Ren Replace Ther 1994; 1:131-147

6. Swedberg SH, Brown BG, Sigley R, Wight TN, Gordon D, Nicholls SC. Intimal fibromuscular hyperplasia at the venous anastomosis of PTFE grafts in hemodialysis patients. Clinical, immunocytochemical, light and electron microscopic assessment. Circulation 1989; 80:1726-1736

7. Roy-Chaudhury P, Kelly BS, Miller MA, et al. Venous neointimal hyperplasia in polytetrafluoroethylene dialysis grafts. Kidney Int 2001; 59:2325-2334

8. Rekhter M, Nicholls S, Ferguson M, Gordon D. Cell proliferation in human arteriovenous fistulas used for hemodialysis. Arterioscler Thromb 1993; 13:609-617

9. Ross R. The pathogenesis of atherosclerosis: a perspective for the 1990s. Nature 1993; $362: 801-809$

10. London G, Drüeke T. Atherosclerosis and Arteriosclerosis in chronic renal failure. Kidney Int 1997; 51:1678-1695 
11. deFilippi C, Wasserman S, Rosanio S, et al. Cardiac troponin T and C-reactive protein for predicting prognosis, coronary atherosclerosis, and cardiomyopathy in patients undergoing long-term hemodialysis. Jama 2003; 290:353-359

12. Morena M, Cristol JP, Senecal L, Leray-Moragues H, Krieter D, Canaud B. Oxidative stress in hemodialysis patients: Is NADPH oxidase complex the culprit? Kidney Int. 2002; 61 Suppl 80:109-114

13. Rostand SG, Drueke TB. Parathyroid hormone, vitamin D, and cardiovascular disease in chronic renal failure. Kidney Int 1999; 56:383-392

14. Amann K, Tornig J, Kugel B, et al. Hyperphosphatemia aggravates cardiac fibrosis and microvascular disease in experimental uremia. Kidney Int 2003; 63(4):1296-1301

15. Lockhart ME, Robbin ML. Hemodialysis access ultrasound. Ultrasound Q 2001; $17: 157-167$

16. Schwarz C, Mitterbauer C, Boczula M, et al. Flow monitoring: performance characteristics of ultrasound dilution versus color Doppler ultrasound compared with fistulography. Am J Kidney Dis 2003; 42:539-545

17. Tessitore N, Bedogna V, Poli A. The role of surveillance in mature arteriovenous fistula management. Journal of Vascular Access 2004; 5:57 - 61

18. Ram SJ, Work J, Caldito GC, Eason JM, Pervez A, Paulson WD. A randomized controlled trial of blood flow and stenosis surveillance of hemodialysis grafts. Kidney Int $2003 ; 64: 272-280$

19. Olsson LF, Odselius R, Ribbe E, Hegbrant J. Evidence of calcium phosphate depositions in stenotic arteriovenous fistulas. Am J Kidney Dis 2001; 38:377-383

20. Catalano C, Davi L, Normanno M, Rizzioli E, Conz PA. Vascular calcification of the venous side of an arterious-venous fistula. Journal of Vascular Access 2001; 2:32-34 
21. Zou Y, Dietrich H, Hu Y, Metzler B, Wick G, Xu Q. Mouse model of venous bypass graft arteriosclerosis. Am J Pathol 1998; 153:1301-1310

22. Grandaliano G, Teutonico A, Allegretti A, et al. The role of hyperparathyroidism, erythropoietin therapy, and CMV infection in the failure of arteriovenous fistula in hemodialysis. Kidney Int 2003; 64:715-719

23. London GM, Guerin AP, Marchais SJ, Metivier F, Pannier B, Adda H. Arterial media calcification in end-stage renal disease: impact on all-cause and cardiovascular mortality. Nephrol Dial Transplant 2003; 18:1731-1740

24. Simonet WS, Lacey DL, Dunstan CR, et al. Osteoprotegerin: a novel secreted protein involved in the regulation of bone density. Cell 1997; 89:309-319

25. Lacey DL, Timms E, Tan HL, et al. Osteoprotegerin ligand is a cytokine that regulates osteoclast differentiation and activation. Cell 1998; 93:165-176

26. Kiechl S, Schett G, Wenning G, et al. Osteoprotegerin is a risk factor for progressive atherosclerosis and cardiovascular disease. Circulation 2004; 109:2175-2180

27. Ridker PM, Morrow DA. C-reactive protein, inflammation, and coronary risk. Cardiol Clin 2003; 21:315-325

28. Ohkuma T, Minagawa T, Takada N, Ohno M, Oda H, Ohashi H. C-reactive protein, lipoprotein(a), homocysteine, and male sex contribute to carotid atherosclerosis in peritoneal dialysis patients. Am J Kidney Dis 2003; 42:355-361

29. Stenvinkel P, Heimburger O, Paultre F, et al. Strong association between malnutrition, inflammation, and atherosclerosis in chronic renal failure. Kidney Int 1999; 55:18991911.

30. Song IS, Yang WS, Kim SB, Lee JH, Kwon TW, Park JS. Association of plasma fibrinogen concentration with vascular access failure in hemodialysis patients. Nephrol Dial Transplant 1999; 14:137-141 
TABLES

Table I: Number, location and mean access flow of stenoses detected at baseline

\begin{tabular}{|c|c|c|c|}
\hline Location & Total Number & PTFE Graft & Native arteriovenous Fistula \\
\hline Proximal segment vein & 16 & 1 & 15 \\
\hline [Qa $\mathrm{ml} / \mathrm{min}$ ] & & {$[730]$} & [450 (210-1050)] \\
\hline Anastomosis & 2 & 1 & 1 \\
\hline [Qa $\mathrm{ml} / \mathrm{min}$ ] & & [1010] & {$[1360]$} \\
\hline Distal segment vein & 32 & 4 & 28 \\
\hline [Qa $\mathrm{ml} / \mathrm{min}$ ] & & [705 (220-890]] & [685 (340-1200)] \\
\hline Total & 50 & 6 & 44 \\
\hline [Qa $\mathrm{ml} / \mathrm{min}$ ] & & [760 (220-1010)] & [545 (210-1360)] \\
\hline
\end{tabular}


Table II: Characteristics of patients at baseline

\begin{tabular}{lccc}
\hline Vascular access & Without failure & With failure & $P$ \\
\hline No. of cases & 109 & 19 & \\
Gender $M / F$ & $61 / 48$ & $10 / 9$ & NS \\
Age years & $68.4[22.3-86.6]$ & $62.7[32.6-82.1]$ & NS \\
Diabetes number & 19 & 5 & NS \\
Smoking number & 31 & 4 & NS \\
Hematocrit $\%$ & $33.70[20.40-45.70]$ & $32.60[23.00-37.10]$ & NS \\
Time spent in HD years & $5.51[0.06-30.28]$ & $8.90[0.11-28.57]$ & NS \\
Kt/V & $1.48[0.23-2.20]$ & $1.46[0.95-2.21]$ & NS \\
\hline
\end{tabular}


Table III: Mineral metabolism parameters with respect to failure of arteriovenous fistula

\begin{tabular}{lccc}
\hline Vascular access & Without failure & With failure & $P$ \\
\hline No. of cases & 109 & 19 & \\
$\mathrm{Ca} \mathrm{mmol} / \mathrm{L}$ & $2.35[1.78-2.66]$ & $2.34[1.82-2.76]$ & $\mathrm{NS}$ \\
$\mathrm{PO}_{4} \mathrm{mmol} / \mathrm{L}$ & $1.42[0.47-3.22]$ & $1.75[0.95-2.77]$ & 0.0416 \\
$\mathrm{Ca} \mathrm{X} \mathrm{PO}$ product $\mathrm{mmol}^{2} / \mathrm{L}^{2}$ & $3.40[1.10-6.80]$ & $4.00[2.00-5.90]$ & 0.0676 \\
$\mathrm{PTH} n g / L$ & $79.50[1.00-846.60]$ & $165.00[1.00-944.00]$ & 0.0814 \\
$\mathrm{~b}-\mathrm{ALP} \mu \mathrm{g} / \mathrm{L}$ & $9.13[0.38-71.32]$ & $12.67[3.24-30.66]$ & $\mathrm{NS}$ \\
$\mathrm{OPG} \mathrm{pg} / \mathrm{mL}$ & $30.54[13.87-124.86]$ & $32.89[18.99-75.49]$ & $\mathrm{NS}$ \\
$\mathrm{RANKL} \mathrm{pmol} / \mathrm{L}$ & $0.19[0.08-4.43]$ & $0.21[0.08-0.74]$ & $\mathrm{NS}$ \\
$\mathrm{RANKL} / \mathrm{OPG} * 1000$ & $6.35[0.64-156.83]$ & $6.71[1.06-24.59]$ & $\mathrm{NS}$ \\
\hline
\end{tabular}


Table IV: Inflammatory parameters with respect to failure of arteriovenous fistula

\begin{tabular}{lccc}
\hline Vascular access & Without failure & With failure & $P$ \\
\hline No. of cases & 109 & 19 & \\
Albumin $g / L$ & $38.20[21.28-47.06]$ & $37.28[28.50-41.78]$ & NS \\
Prealbumin $g / L$ & $0.30[0.07-0.53]$ & $0.29[0.13-0.44]$ & NS \\
CRP $m g / L$ & $6.20[0.32-90.40]$ & $7.46[0.70-62.60]$ & NS \\
Orosomucoid $g / L$ & $1.22[0.60-2.40]$ & $1.21[0.77-1.96]$ & NS \\
\hline
\end{tabular}

